Then gradually the quantity of Cholera fluid lessens, and finally, bile pigment appears, and the stools lose altogether the Choleraic character.

Want of space compels me to dismiss these most important topics, with theflindication merely of the chief points of interest. I hope on a fycure occasion, to be able to adduce additional facts in corroboration, or mgdification of my views, and to enter more fully into the question of the relation of the individual elements of the Cholera dejections, to the general phenomena of the disease.

Contributions to the PATHology and TREATMENT OF TROPICAL FFVERS.

By JAMES BIRD, A.M., M.D., formerly Surgeon to the European General Hospital at Bombay, and late Physician General, Bombay Army.

(Continued from p. 60.)

1II. REMITTENT FEVER.

The tendency of intermittents, when unchecked, to pass into remittents, and of the latter to change again to the intermittent form, during the transition from the hot to the cold season, shows the intimate relation of these varieties of fever. In 1821, the rainy season at Kaira was unusually light, the weather consequently hot, producing among the men of the Horse Artillery a great amount of hepatic disease, but comparatively few cases of remittent fever. The latter, however, was prevalent in H.M. 17th Dragoons, who were located leerard of fertile, marshy ground that lies south of the cantonment towards Cambay; while the site of the latter was lower and more favourable to malarious emanations, than was the locality of the Horse Artillery Burrack. Here a slight elevation and comparative dryness of soil produced only intermittents and attacks of hepatic disease ; there a lower level and damper situation, abounding with pools of water, which dried up as the weather got hot, gave origin to remittents.

The Kaira district of Gujerat, in which the dragoon cantonments were situated, is a flat, sandy country, where the land is well cultivated and fertile, producing abundance of rice, wheat, and other grains. The soil is a mixture of sand and vegetable mould, the substratum of which is a granular carbonate of lime, here and there elevated into hillocks, or sloping in gentle declivities towards the beds of the rivulets, which have a slow, almost stagnant, course towards the sea. The nature of the soil, and flatness of the land, admit of the country being easily flooded during the rainy season, which begins in the middle of June and continues till the end of September. While the rain is actually falling, intermittents and dysenteries are the prevailing complaints; but towards the termination of the season, when vegetable decomposition begins to take place, and the vapour which arises from damp situations during the day is seen at evening to hang over them in the form of a white haze, remittent fevers of a violent nature become general. From the middle of September to the middle of November, when the climate is humid, hot, and oppressive, these fevers rage with great severity, and in various forms, according to the peculiar atmospheric condition of particular seasons, and prove very fatal to recentlyarrived Europeans. 
In the beginning of June, 1822, the 4th Dragoons, from Europe, relieved the 17th Dragoons at Kaira. The former regiment, about 600 strong, was, in a great measure, composed of healthy young men from the labouring class, very few of whom were under eighteen years of age, or beyond the period of middle life. Soon after their arrival at the station, the rainy season commenced, with squalls of wind from the S.W. The rain was continuous and fell heavily during August, when the maximum of the thermometer fell from $94^{\circ}$ to $90^{\circ}$ of Fahrenheit. About the 20th of September the monsoon ceased, the days were hot and sultry, and generally a heavy dew fell at night. The first part of October was also sultry and oppressive, though there were occasional showers. Towards the end of this month the wind changed from S.W. to S.E., and there were thick morning fogs on the ground, which never dispersed before the sun had attained a considerable height. While the rains were falling, the prevailing diseases, in the 4th Dragoons, were bowel complaints and intermittent fever; and among the men of the Horse Artillery, rheumatism and fevers of a mild type. Among both bodies of men, however, severe remittents were generally prevalent in the end of September, and proved very fatal to those of the dragoons: this regiment having lost, from the beginning of June to the end of December, three officers, fifty-one men, seven women, and twenty-seven infants and children, chiefly from fever and bowel complaints. In the same period the horse-artillery lost six men, of whom five died from remittent fever, and the other from chronic hepatitis. In the end of November the cold weather set in, and the intermittents admitted into hospital from this time were attended by better marked symptoms of hepatic affection, and a less violent hot stage, than had characterized fevers of the same type in October. On the 2nd of December the horse artillery marched from Kaira en route to Poona, passing through a country where mourah and other strong spirituous liquors were easily and cheaply procured. Many of the men were consequently often intoxicated, and were exposed to the influence of causes that usually produce fevers of periodicity, viz., jungle or thick brushwood, and long rank grass, existing in the district between the rivers Nerbudda and Tapti. Extreme variations of temperature between the heat and cold of the days and nights, which happened at this time, gave great energy and effect to the malarious causes originating from these sources, and which, in this instance, appear to have acted rather as predisposing than as exciting ones, in giving rise to fevers of great severity. The variations were sometimes so great as $30^{\circ}$ of Fuhrenheit, the thermometer standing at $85^{\circ}$ during the day, and descending so low as $54^{\circ}$ at night. The two troops of horse-artillery from Kuira joined, on the 2nd January, 1823, the relieving bodies on their march from Seroor, and both divisions halted at the station of Baldipara, in the neighbourhood of the Portuguese settlement of Damaun. Here all the troops were encamped for several days, leeward of an extensive tank and marsh, over which a north-east wind was constantly blowing ; and before many days a severe bilious remittent fever, attended by symptoms of congestion, broke out among the men from Kaira, and proved fatal to three of the nineteen attacked. The influence of the morbific predisposing causes, intoxica- 
tion and former febrile attacks, was developed in the production of severe fever among those from Kaira; while the more robust and healthy subjects from the Dekhan, not exposed to like causes, continued free from fever during the whole period of our encampment.

The conversion of intermittents into remittents follows, as we have shewn, increase of temperature and augmented malarious influence; being dependent, as would appear, on increased nervous irritability, chiefly affecting the cerebro-spinal and grand sympathetic circle of nerves, as will be presently illustrated in the pathology of these fevers. The modifications of them which $I$ have observed in different parts of India, may be described as four varieties: 1st, Simple or uncomplicated remittent ; 2nd, Inflammatory or complicated ; 3rd, Asthenic or congestive ; and $4 t h$, The typhoid. The first is the most common form of remittent met with in Bombay ; the two next are those usually affecting young, healthy European subjects in Gujerat, or soon after their arrival within the tropics; and the last may be either the effect of over treat. ment, particularly profuse bloodletting, and the too free use of purgatives; or the primary effect of weak constitutional powers, and the concentrated application of endemic causes, and cold. The assemblage of symptoms, characterizing these diversities of tropical remittent, is useful for practical purposes, and the phenomena distinguishing each may be described as succinctly as possible.

Simple Ramitent.-In this the febrile symptoms crept slowly on, the patient at first complaining of extreme lassitude without any adequate cause, slight headache and pain of the limbs, loss of appetite, and occasional uneasiness at the epigastrium. The features were pale and shrunk, the eyes dull, heavy, and listless, with occasional chills running along the spine. The tongue was either covered with a thin white film, or yellow and loaded, but generally moist. The bowels were, for the most part, constipated, and the pulse small and frequent. This period of nervous depression was succeeded by symptoms of reaction : the pulse and skin increased in volume and temperature; the headache became more severe, with occasional delirium, accompanied by nauser at the stomach and vomiting of bilious matter. The tongue was now dry and furred, the thirst great, the urine high-coloured and scanty, and the patient complained of a painful sense of weariness, causing a constant desire for change of posture. In most cases these symptoms had a well-marked diumal exacerbation and remission, almost amounting, in the slighter forms, to intermission ; and after a period, varying from three to six days, were partially relieved by a general warm perspiration appearing on the skin, indicating that, though the secretions from the liver, kidneys, and intestinal mucous surface, were impeded and deranged, there was still no actual inflammation of these organs, which seemed to be only functionally affected. The increased or diminished temperature of the skin, and the greater or smaller volume of the pulse, mark well the remittent character of the fever, and should be carefully olserved both during the day and at night, particularly as midnight is found in many instances to be the time of the exacerbation.

This species of mild, uncomplicated, remittent fever, is that usually met with among the sipahies of our native regiments, and in European constitutions, where the sanguineous temperament is not strougly de- 
reioped, and where there are no indications of high nervous mobility. It is not, therefore, associated with a phlogistic state of the blood, or marked inflammatory action in any of the organs, unless allowed to proceed uninterruptedly, or without efficient treatment, till the third, or sometimes the sixth day : at which periods the disease, from having, as appeared, the tertian type, showed a disposition to natural crisis and relief of all the symptoms. But when the perspiration, which broke out at these periods, proved imperfectly critical, there was generally, about the sixth day, a tendency in the disease to terminate in partial collapse, with congestion of some important organ,- the liver, spleen, or brain. This state was followed by a stage of reaction, to which succeeded well-marked inflammatory affection of some of these parts, converting this originally mild variety of remittent into the more severe inflammatory species; which, when proceeding from high health, phlogosis of the blood, and much derangement of the secretions, may be an original disease.

InFLAMMATORY REMitTENT.-In this all the symptoms characterizing the mild form were increased in degree, and were present in the cases admitted into hospital during the extreme heat that took place in the end of September and beginning of October. The patients described the chilliness as running along the spine in distinct shocks; to which succeeded excruciating headache, flushed swollen countenance, hot dry skin, much irritability of stomach, great thirst, severe aching pains in the loins and lower extremities, and a very frequent, bounding, but compressible pulse. These symptoms, for the most part, suffered a remission at night, or towards morning; but the ascension of the sun, and the extreme heat after noon, brought with them an exacerbation. In some instances, the remission seemed more remarkable and distinct on the morning of the odd, than of the even day, arising, probably, from the original type of the fever being tertian; but in others, the symptoms were nearly continued, and not marked by any very distinct remission. The salivary secretion was very defective and viscid; the tongue either covered by a white slimy crust, or furred and parched. In the latter case, the thirst was most distressing - amounting, indeed, to agony-in the height of the exacerbation; so that patients even derived relief from exposing the tongue to the air. The biliary and cutaneous secretions were defective; and the urine sometimes so acrimonious as to create strangury. The temperature of the surface, measured by a thermometer, was $105^{\circ}$. Some of the patients had a fixed pain at the vertex of the head, and tenderness of the scalp. One also had tenderness along the course of the spinal canal ; so that pressure on the cervical vertebræ immediately produced an inclination to vomit. Extreme giddiness was a bad symptom; and was connected, as appeared, with much venous congestion of the brain. The severity of pain in the extremities seemed proportionate to the cerebral affection. One patient had delirium; and the sleep of all was much disturbed. There was great oppression at the chest and epigastrium; and the respirations were short and quick. The pulse, at the height of exacerbation, was generally $140^{\circ}$; and did not fall lower than $118^{\circ}$ during the remission. Its strength varied throughout the day, and rose in proportion to the heat of the atmosphere. In the morning, when the 
air was coolest, it was small and frequent; but at three o clock in the afternoon, during the greatest heat, it was full but compressible. The biliary function was deranged from the commencement of the disease, though there was seldom pain in the region of the liver, until the fever had been of severul days' duration. There was frequently deficiency of bile in the alvine evacuations; though sometimes its presence in the stomach, and in too great quantity, created nausea and oppression. The alvine evacuations were sometimes as black as tar; but varied from this to a leaden brown and dark yellow colour. Many of the patients, previous to the development of the febrile symptoms, had been passing large quantities of mucus by stool ; and, under such circumstances, the prognosis was unfavourable, as the whole intestinal mucous surface seemed to be in a state of morbid vascularity.

Congestive, or Asthenic Remittent,-is distinguished by great languor and drowsiness, mental depression, and pain in the head, attended by a sense of constriction, as if a band compressed the brain. There was much anxiety and oppression of the præcordia, general defective condition of the secretory functions, accompanied by an oppressed, feeble pulse, and cold, moist, clammy skin. These symptoms were seldom preceded by attacks of chilliness or shivering, as in the two former varieties; but were attended by continued sense of cold and tendency to collapse, as in cases of cholera, and without any well-marked general reaction; there being, in this stage, partial flushings of the face, heat of hands, or greatly increased temperature at the epigastrium and over the abdomen. The eyes were sunk, and injected with blood; and the tongue clammy and moist. The phenomena of this variety have been correctly attributed to suspended function of the cerebrospinal and great sympathetic nerves, attended by depressed action of the vascular system, and follow the intense sedative influence of the malarious poison. In some instances, however, met with at various times, the symptoms seemed to be connected with long-standing disease of the liver, kidneys, and central organ of circulation.

Trenoin Renitrent. - When this form of the remittent appeared as an original disease, the symptoms continued for two or three days, without distinct remissions or exacerbations. There were much tension and tenderness at the epigastrium; nausea, or vomiting; the skin was harshly dry and hot; the tongue parched and brown, or sometimes furred in the centre, and red at the edges; the alvine evacuations were dark and offensive; drowsiness or muttering delirium, a feeble, frequent pulse, tremor of the hands, sordes of the lips and gums, and occasional subsultus tendinum, were present. In other cases, where the symptoms were the effect of too free blood-letting, or the injudicious use of purgatives, the stage of vascular excitement, observable in the two first varieties, gave way to indications of extreme nervous depression and general atony of the vascular system. The patient's headache was succeeded by drowsiness and starting of the tendons, in some cases, and by restlessness and febrile anxiety in others. The respiration became quicker and shorter; the temperature of the skin fell below the natural standard; the countenance grew pale and haggard; the tunica albuginea of the eye became of a yellowish hue, or there was general bilious suffusion of the skin; the tongue became black and dry; the 
teeth covered with sordes; and the gums sphacelated, where calomel had been administered too freely, with the view of obtaining its constitutional effect. Mr. Mardon, formerly of the Bombay Medical Board, and now residing in London, has described, in Johnson's Medical Magazine, a fatal fever of this kind, which prevailed, during the month of June 1818, in a detachment of the Bombay European regiment, doing duty in the garrison of Surat. The detachment consisted of ninety-four men, who occupied a damp, ill-ventilated building, formerly used as a mint ; and, being much crowded together, fifty-three out of the whole were attacked by severe fever. The leading symptoms of this, were great prostration of strength and irritability of stomach, acute headache, pallid lips and tongue; transparent, horny-looking gums; generally sunk and cadaverous expression of the countenance, though in some it was much flushed. The pulse was frequently hard and strong. Some of those attacked were brought to the hospital in a state of stupor, from which they did not recover for several hours. Calomel was at first used, in order to obtain its constitutional effects ; but the head soon bec ıme swollen, the parotids enlarged and indurated, accompanied by sphacelation of the gums, and other symptoms of putridity. The treatment was successfully changed to moderate blood-letting, sponging of the body with cold water and vinegar, and saline effervescing draughts, to relieve thirst and reduce the heat of skin, followed by the free use of bark combined with diluted sulphuric or nitric acid.

Post-mortem Appearances. - A minute examination of the bodies of those who died of remittent fever in Gujernt, was made in every instance; and though the morbid appearances varied somewhat in different cases, they were in general such as to identify similarity of action having existed in all varieties of fever. They were in no respect different from what $I$ afterwards met with in the remittent fevers of Bombay and other parts of India, excepting that, in Gujerat remittent, there were indications of the cerebro-spinal axis and great nervous centres being in a better marked state of hyperamia than they were observed to be in other instances. Most of the fatal cases at Bombay occurring in men of more advanced life, the intestines were more frequently softened or ulcerated, the liver enlarged and pale from former disease, the spleen pulpy, the lungs adhering to the parietes of the chest, with the accompaniment of fibrinous polypi in the heart. It will be impossible, within the small compass allowed in the Journal, to give the detail of particular cases. I must content myself, therefore, with giving as specific and correct an analysis of the appearances as the sulject will admit of.

Brain and Spinal Column. - The immediate cause of death seemed to be effusion of serum betwixt the pia mater and tunica arachnoides, or into the lateral ventricles. If the patient died early, venous congestion of the substance of the brain was strongly marked, by the cut surface of the medulla becoming instantly covered with numerous bloody points, and by the pia mater being of a livid colour. But when the patient died emaciated, the bloody points were fewer, and the vessels of the pia mater contained large quantities of air. Where delirium had existed, the pia mater was inflamed through the whole substance of the brain. The theca vertebralis always contained more or less fluid, and 
in one instance its cellular sheath was very vascular, and had a gelatinous appearance throughout. In this case a considerable quantity of albuminous fluid had been effused betwixt the tunica arachnoides and the pia mater of the medulla spinalis, immediately opposite the seventh dorsal vertebrum. The white substance of the medulla oblongata and me lulla spinalis, and the ganglia of the great sympathetic, were in a highly vascular state.

Cuest.-The lungs were only fully collapsed in one instance, and in this there was no appearance of pulmonary disease. In all other cases there was general congestion of the lungs, or pulmonary apoplexy of their substance, the ecchymosed tumours being harder than the rest of their structure, appearing, on a section being made of them, to be formed by the extravasation of frothy blood into the part. In one instance there were yellow crude tubercles in the lungs, and here the pleura costalis contained eight ounces of bloody serum. From half an ounce to six drachms of yellow serum were generally found in the pericardium.

Abdomen. - The liver, which had in many cases suffered from previous chronic disease, was in a state of congestion, attended with extravasation into the hepatic parenchyma. The gall bladder was filled with thick black bile. The mucous coat of the stomach was very red and vascular near the pyloric orifice, sometimes softened and mammillated, and in one case, where the mouth sphacelated from mercury, it was of a dark leaden colour. Occasionally where the stomach was vascular, the mucous coat of the duodenum, which contained an ash-coloured slime, was normal; but the mucous lining of the jejunum and ileum was, in recent cases, red and vascular, and in those of some weeks' standing of a dark grey colour. The spleen was soft and pulpy. In many instances the mesenteric glands were enlarged, and the pancreas more indurated than natural. The kidneys, when examined, were in a state of hyperæmia.

Pathology of Remitient Fever.-Intermittents so far differ from remittents that $t^{\prime}$ 'e nerrous irritation and increased action of the circulating system are of only tempornry duration, and terminate by an increase of the secretions, functionally suspended; while the latter, either associated with a more phlogistic state of the blood, more acute irritation and hyperæmia of the cerebro-spinal axis, und great nervous centres, are seidom disposed to a crisis, or return of natural actions, after the exacerbations, unless assisted by the interference of art. There were certrinly occasional cases of remittent, under the influence of change of air, and removal from the site of the miasma causing them, which terminated by a remarkable increase of biliary secretion, constituting what is called hepatic erethism; but in general the vis a tergo and the natural power of the constitution were not sufficient, as in intermittents, to overcome the resistance offered by the capillaries of the skin, and the congestion of other secretory organs; and when no longer capable of doing so, simple remittents assumed an inflammatory or continued form. "The phenomena attending remittent fevers in Gujerat, und in other parts of India, indicated compound affection of the nervous, circulating, and secretory systems ; the first of which, in new comers, seemed to be primarily affected by the sedative action of malaria on the blood; but, in cases of relapse, and in the constitutions 
of long residents, rendered extremely sensitive of sol-lunar influence, altered and diseased secretion of some of the chylopoietic viscera were first observable in the chain of morbid effects; and to this succeeded the nervous depression, and subsequent irritability of the sensorium and nerves, which became manifest. The same reflex action of abdominal irritation, caused by improper food, or the presence of worms, in cases of infantile remittent fever, is seen to produce, secondarily, such an increase of carbon in the blood, and accumulation of blood in the venous system and right side of the heart, as often take place in idiopitthic cases of remittent fever, wherein such morbid effects are considered primary. The arrangement of fevers into idiopathic and symptomatic is therefore of questionable propriety, as would be the forms of cholera, which are, under general epidemic influence, primary, but often secondary when arising from improper food, or the abuse of intoxicating liquors, favoured by the action of endemic causes, preventing the complete arterialization of blood in the lungs, and increasing the quantity of excrementitious matter in the circulating fluid.

Those who have witnessed pernicious remittent fevers, like those of Gujerat, must have remarked that when the bile was deficient or changed in quality, the appetite languid, and the tongue loaded, there were symptoms of muscular debility, pallor, and coldness of the feet and skin, and increase of the intestinal mucus; that the nutrition of the body was imperfectly performed, the qualities of the fluids consequently changed, accompanied by constitutional irritability, followed by increased temperature of the skin and volume of the pulse. They must have also become sensible how absolutely necessary to good health are the depurating functions of the liver and intestinal surface, assisted by those of the kidneys, skin, and pulmonary respiration; and can scarcely wonder that in fever, where all these functions are suspended, the best directed efforts of the physician should frequently prove unsuccessful for the cure of so formidable a malady, as is the marsh remittent of warm climates. I will endeavour to analyze and describe these successive changes as they occurred in fever, knowing how necessary it is, for the object of successful treatment, to attentively watch and consider them during the progress of the malady, and in all its modifications.

Though unacquainted with the exact nature of the poisonous exhalation, or malaria, causing intermittents and remittents, we are yet capable of tracing its effects on the human constitution. These vary in grade according to the greater or less intensity of the cause applied, and the predisposition of individuals affected; giving rise to every type and modification of fever. The only visible morbid changes produced by such cause are to be traced in the vascular system of the several organs, with whose functions in a healthy state, and with the laws that regulate them, we become acquainted through the discoveries of physielogy. Combining such knowledge with the post-mortem appearances in Gujerat remittent, and in other diseases, such as cholera, having an algide stage, I ascribe the whole series of febrile phenomena to loss of vitality in the blood, consequent accumulation of it in the right side of the heart and venous system, hyperæmia with defective action in the brain and spinal marrow, and temporarily suspended secretory functions of the liver, intestinal surface, kidneys, and skin. Thicse, with the 
suspension of the respiratory functions, and necessary chemical changes of the blood that produce animal heat, give rise to the cold stages both of fever and of cholera. The subsequent reaction and excitement accompanying the hot stages of intermittents, and the exacerbations of remittents, and also the febrile stage of cholera, are clearly referrible to an increased flow of blood through the spinal marrow and dependent nerves, which are in a state of hyperæmia with increased motion, and give rise to those copious secretions of bile and diarrhœeal discharges from the intestines, by which nature, in healthy constitutions, endeavours to relieve herself, and to restore the blood to a healthy purity. The pathological condition, then, of simple and inflammatory remittents, must be considered as hyperamia and active irritation of the spinal marrow and nervous centres, which supply the great abdominal organs of secretion. When these organs are in a healthy state, and capable of relieving themselves from the increased determination ef blood to them in febrile action, by supporting an increase of their secretions, remittent fevers are met with in their mildest form, and are curable by the gentlest appliances of art. But when, (through intensity of malaria, previous disease, original weakness of constitution, or two great pressure or oppression of the circulating fluid in its vessels,) becoming incapable of carrying on their ordinary functions, they are left in a state of asthenic hyperæmia or congestion, and sometimes of secondary inflammation, with diminution of the red particles of the blood, there are respectively constituted the congestive and typhoid modifications of remittent. These, as far as I have been able to discover, are the phenomena or series of changes which take place in primary or idiopathic fever.

In relapsed cases of the remittent, however, where no fresh application of malarious causes could be deemed instrumental in producing disease, morbid excitement appeared to commence with derangement of the digestive organs, and irritation of the intestinal mucous membrane; which irritation, extending through the great sympathetic to the cerebro-spinal axis, probably produces the same change on the blood and secretions, as those associated with the phenomena of idiopathic fever. It is only in this manner that the periodicity of infantile remittent fever, when not of primary malarious origin, cau be accounted for. In constitutions rendered irritable by long residence within the tropics, the same reflex nervous irritation is produced by a change from a tropical to an extra-tropical climate, by the influence of cold on the skin, or the prevalence of east wind, without the aid of fresh malaria.

Treatment of Remittents. - It would be impossible for me to here enter on the mode of operation by which particular remedies equalize morbid excitability and diminish febrile action, and I must, therefore, limit myself to the general system of treatment which $I$ have found most efficacious in remittent fever. The general principle kept in view, with the constitution in a state of sthenic plethora, was to reduce the quantity of blood in the vessels, and diminish nervous excitability, by one or more general blood-lettings of twenty ounces from the arm, according to the fulness of the pulse, and tone of the constitution. Immediately after the bleeding, from ten to fifteen grains of calomel, uncombined, were given along with a saline effervescing draught, com- 
bined with a drachm of ipecacuanha wine and an equal quantity of nitrous ether. The head, being the part chiefly affected, was shaved, and the cold douche employed to reduce febrile heat during the exacerbations ; or cloths, wetted with vinegar and cold water, were kept constantly applied to the head, the hands and arms also being sponged with the same cooling lotion. The administration of the calomel, when the stomach was free from irritability, was followed by a brisk purgative of compound senna mixture and Ersom salts, or compound powder of jalap, in order to remove the disensed secretions from the bowels. During the next exacerbation, if a second general bloodletting were required, it was repeated with caution ; for in the country of Gujerat, where the thermometer, in the month of October and part of November, rose to $90^{\circ}$ at three o'clock in the afternoon, the pulse of those suffering from remittent was found at this hour 130, and secmed to possess even firmness and strength in cases where the constitution had been worn down by former disease. At the period I first went to Gujerat, it was a common practice, in accordance with the doctrines of the day, to bleed largely in all cases of fever, under the erroneous supposition that fever and inflammation were much akin, and required the same amount of depletion. A very short experience in the remittents of the country convinced me of the danger arising from such a practice; and I soon learned that in so hot a climate I could not follow such a deceitful guide as the pulse, to direct me in deciding on a repetition of bleeding. The medical men of that day were too apt to form their ideas of treating fever from the vascular action accompanying its exacerbations, and to overlook the irritability of the sensorium and nervous system, which no amount of bleeding could diminish. In accordance with prevailing opinions, I was therefore induced, in the earlier sears of my practice, to repeat the venesection two or three times; but became convinced, by subsequent experience, that more than two general bleedings were seldom necessary in inflammatory remittents disposed to assume a continued form. The corgulum of the blood, in the fevers of Gujerat, was for the most part very loose, and in large proportion to the serum; and as such a condition of it indicates no very great tolerance of the constitution for large abstractions of blood, and remittents of this kind were, after a few days' continuance, disposed to assume the typhoid character, it was better not to have recourse to repeated renesection. The local determinations, which become developed in the paroxysms, are more safely controlled by leeching or cupping, and by giving disulphate of quinine, in divided doses, along with small quantities of antimonial powder or ipecacuanha, and effervescing draughts with diuretics, to prevent the recurrence of the paroxysm, and obviate secondary inflammatory effects.

Mr. Mardon, in his treatment of the Surat remittent before alluded to, repeated the bleeding two, three, and four times, and says :- "In many, the first bleeding was sufficient to arrest the disease. Calomel was only used as a purgative before the administration of bark, which was administered with diluted sulphuric or nitric acid, before the exacerbations. Forty-eight men, out of fifty-three attacked, completely recovered by this treatment, after the practice of endeavouring to obtain the constitutional effects of calomel had proved most unsuccessful, and 
was attended by extreme symptoms of putridity in the constitutions of the patients subjected to this mode of treatment." I would not, however, recommend, even in extreme cases, more than two general bleedings, knowing how easy it is, when quinine is properly administered in the remissions, to control the febrile heat and excitement of the exacerbations by cold douche to the head, and ablution of the body, wi. $\because 9$ there is neither diarrhoea nor symptoms of inflammation in any of the abdominal viscera. The cold ablution of the body, during the height of the exacerbation, usually reduced the pulse twelve or fifteen beats for nearly an hour after its use, and if the heat of skin increased much and was persistent, it was necessary to repeat the remedy, and to keep the patient's head cool by wet applications. Every increase of irritation, every exacerbation of the remittent, appeared to commence in the brain, and extend along the spinal marrow, and were, in severe cases, subdued by the application of leeches to the temples. But douche to the head, und general cold ablution, are the remedies most to be relied on in moderating the exacerbations of Gujerat remittents, whose paroxysmal returns are to be prevented by quinine or the bark. In using cold ablution, it was not deemed necessary to delay it till the height of the exacerbation ; for to this there are objections, of which not the least is that febrile heat is allowed to greatly increase, and to be reduced with less chance of a favourable termination.

In the mild remittent form which occasionally affected Europeans, and is that generally met with among the natives of India, an emetic of five grains of ipecrcuanha, given at the commencement, was successful in breaking the chain of morbid phenomena; and when followed up, at bed-time, by small doses of mercury and chalk, a purgative the succeeding day, and then quinine to prevent the return of the paroxysm, seemed to be the best remedial measure for this kind of fever. Sometimes, in Europeuns, a single general bleeding seemed necessary; but there were very few cases among natives of India wherever it was requisite. With the latter, mercurials should be sparingly employed; as the constitution and habits of our Sipahies are such as to render the fres use of calomel dangerous to them. These men, when not on duty, expose themselves without clothing to the air, bathe daily in cold water, and cannot be strictly controlled in their diet. To such, the constitutional effect of mercury proves most prejudicial ; and in regiments where the practice is resorted to, the annual invalid list is found increasing to a remarkable extent, the men becoming martyrs to rheumatism and glandular disease.

In the congestive form of the remittent it was usual to administer quinine combined with calomel, antimonial powder, and scammony, if the bowels were confined; or with small doses of opium when there was diarrhoer. The patients were put in a hot bath at the temperature of $105^{\circ}$, and when laid again in bed, were allowed to drink freely of equal parts of saline and camphor mixture, in doses of three ounces, with the addition of half a drachm of nitrous ether. Partial congestions, marked by a great increase of heat in the forehead, or at the pit of the stomach, were relieved by cupping or leeching; and in such cases friction of the spine with stimulating embrocations, or the application of a large blister to the part, should never be neglected; as here 
the state of hypercemia, with defective innervation, must be considered as the source of the symptioms attending this modification of fever. Stimulating enemata, composed of castor oil and oil of turpentine, may be also usefully employed in such cases. Whenever it may be deemed advisable to relieve the general distention of the vessels by bleeding, venesection should be performed while the patient is in the hot bath.

When the fever assumed the typhoid character, and there was increased temperature of the surface, the general principles of treatment were-tepid sponging of the skin ; saline mixture, with diuretics, enemata, or gentle purgatives; and light nourishment, such as thin arrowroot, with small quantities of wine; or the yolk of an egg, mixed up sagar, nutmeg, wine, and hot water. As soon as the symptoms showed any tendency to remission, sulphate of quinine, with antimonials, saline mixture, and diuretics, were given to restore the healthy energy of the nervous and circulating systems; and to depurate the blood, by increasing the urinary secretion. In this modification of remittent, the chemical condition of the blood is altered, its red particles are deficient, and sometimes, from containing urea, it produces symptoms of oppression and coma. The employment of certain diuretics, therefore, at this stage of disease, forms an important element of treatment.

Infantile Remittent. - It is not my intention to enter at length on the consideration of this disease, which, in the form of gastric and bowel complaints, associated with febrile symptoms, proves so fatal to the infants and children belonging to newly-arrived European regiments. The relation of this disease to the tropical remittent of the adult, has been already pointed out; and the same morbid enlargement of the muciparous and mesenteric glands, congestion of the liver, softened and enlarged condition of the spleen, red vascularity of the mucous surface of the stomach and intestines, engorgement of the lungs, congestion of the brain and serous effusion into its ventricles, are observable after death in both. The remittent of infants, according to my own observations, either happened as a primary disease, caused by malaria ; or occurred as a secondary one, proceeding from gastric irritation, induced by cold, damp weather, improper food, and teething. Like other fevers, $I$ have found it terminating in mesenteric enlargement and marasmus, by which the child was reduced to extreme emaciation; or it occasionally ended in albuminous nephritis, with effusion into the abdomen, and anasarcous swelling of the legs.

The treatment of this disease must be conducted on the principle that it is more a disease of irritation than is the remittent of the adult; and the abstraction of blood to relieve local affections of the head or stomach, must be used more sparingly and with greater caution. The safest and most effectual management of this disease is to give repeated emetics of ipecacuanha wine, at the commencement of symptoms indicating the exacerbations, and to follow up these by administering small doses of mercury and chalk, with Dover's powder, or a saline draught containing ipecacuanha wine, after having previously used a warm bath at the temperature of $98^{\circ}$ or $100^{\circ}$ of Fahrenheit. If the aldominal pain appears great, a hot poultice or mustard cataplasm should be laid over the stomach, and diseased secretions from the bowels are to be removed by gentle doses of castor oil. The cerebral excitement and disposition 
to drowsiness accompanying this disease are so frequently the effect of reflex nervous irritation from the abdomen, that the too free use of calomel or of purgatives must be avoided ; for, when the Indian treatment of infantile remittent was to purge children with calomel till the greenish bilious motions became of a healthy yellow colour, I have seen patients thrown into a state of coma by the continued irritation kept up in the mucous membrane, and from which they soon recovered on this treatment being discontinued. Small doses of quinine, given with mercurials, are useful in preventing the recurrence of paroxysms in the child as well as in the adult.

\section{CONTINUED FEVER.}

The ardent fever which prevails among recently-arrived Europeans, during the hot weather, is essentially a disease of the vascular and secreting systems, brought on by elevated temperature and excessive spirit-drinking, acting on the irritable fibre and excitable constitution of those in robust health. The changes effected in the blood by such causes, acting through the medium of the cerebro-spinal axis, are probably the same that take place in genuine remittent fever; but the continued ardent fever of the hot season must be held as a disease which originates quite independently of malarious causes, and is more nearly allied to gastritis and acute hepatitis than to the usual forms of pure remittent. Among bodies of men previously exposed, in marshy countries, to mularia, it may be met with assuming all the characters of continued inflammatory remittent; but in such cases it must be rather regarled as relapsed remittent, thiun a genuine continued ardent ferer. It is, as before said, more exclusively connected with accelerated arterial action, and tonicity of the vascular system, than are other kinds of fever; though, under great exposure to the sun and excess in drinking, it is found occasionally in a congestive form.

The symptoms characterizing this type of fever, are-greater pain of the head and flushing of the countenance, more persistent heat of skin, firmer and harder pulse, tongue whiter or more furred, urgent thirst and higher coloured urine, accompanied by a red ferrety expression of the eyes, as in men bordering on attacks of delirium tremens. In the sthenic form of this particular fever, the headache is chiefly frontal, being attended with aversion to light, contracted pupil, and heat of the scalp, with flushing and heat of the neck and breast. But in the asthenic or congestive variety, which follows excessive drinking, and much exposure to the heat of the sun, the patients complain of vertigo, accompanied by dilatation of the pupil, a clammy and sometimes rather cold state of the skin, a low soft pulse, and other symptoms of depressed nervous energy. More severe attacks of this congestive type present the appearance of coup de soleil, the patients being in an insensible state, the face livid, the eyes suffused, the breathings stertorous, accompanied by hot skin, and an oppressed labouring pulse, which sinks rapidly when venesection is employed at the outset of the attack.

From the great similarity existing between continued tropical fever, and the hepatic and cerebral affections of Europeans in hot climates, some have denied the existence of anything like continued fever within the tropics; but a few weeks' experience, during the hot season in 
Gujerat, and among lately arrived European troops, would soon convince them of the fallacy of such an opinion. This fever, like other similar affections, is met with, modified from a strong and well developed action of the vascular system, where general blood-letting can be borne well, to a congestive state of the blood-vessels, with depressed nervous energy, where bleeding, except by cupping, must be used with the greatest caution. In most cases of this disease, the stomach, after death, presents a highly vascular appearance of its mucous coat, accompanied by general congestion of the mesenteric veins; the liver is engorged with blood, the gall-bladder distended by green or ambercoloured bile, and the membranes and substance of the brain in a state of extreme congestion. In many cases, the liver and stomach seem to be the organs primarily affected, being followed in the course of the disease by cerebral symptoms; but the development of those presenting themselves in this fever varied considerably, according to the exciting causes to which patients had been exposed; cerebral ones being the more prominent where solar radiation had the lead in bringing on the attack, and hepatic or gastric ones, where excessive drinking had produced the fever.

The treatment must consist of general blood-letting, according to the circumstances and severity of the case ; repeated cold affusion, to subdue the increased temperature of the skin; calomel, with antimonial powder and opium; active purgatives, with leeching and cupping of particular parts, where symptoms of inflammation or congestion appear. Quinine, with saline mixture and diuretics, become necessary after the more active symptoms are subdued; and in this type of fever, the constitutional action of mercury may be employed with more success than in cases of marsh remittent. The superior efficacy of this remedy, in the continued ardent fever, appears to depend on the blood being more fibrinous than in remittents.?

1 Clinical cases in illustration, and mnch more relative to continued fever, are here neces. sarily omitted, the limits allotted to me having been already somewhat extended.

jCASES OF REMTTENT FEVER. 


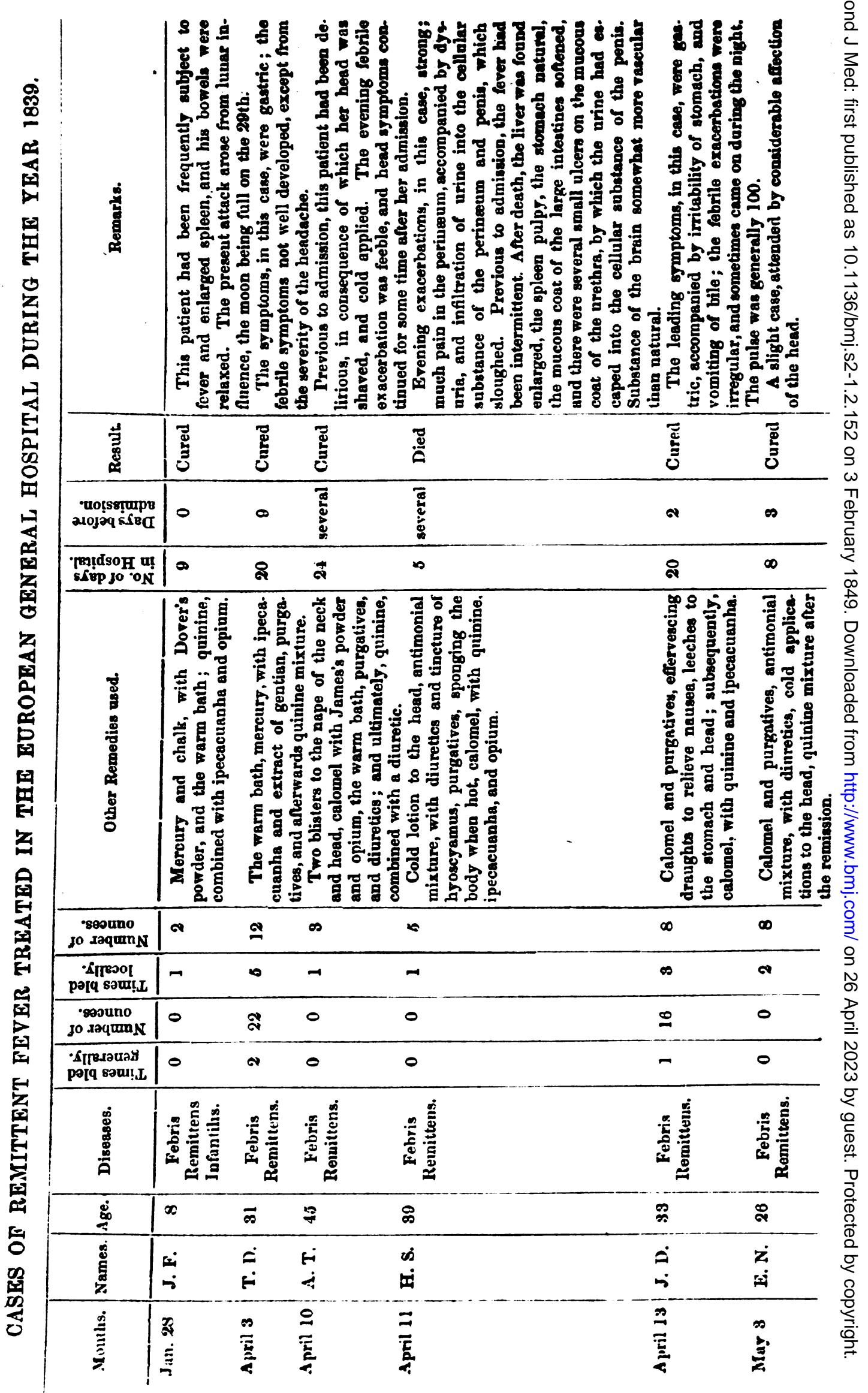




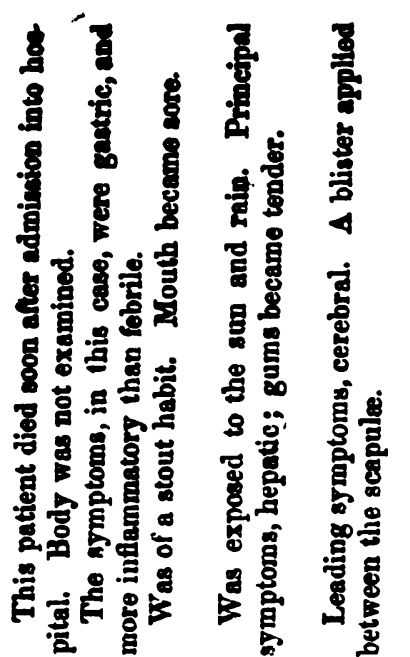

III

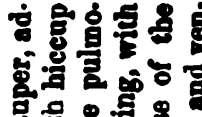

동홀

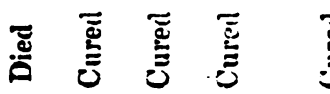

\section{$\bar{\Xi}$}

莺

㻤

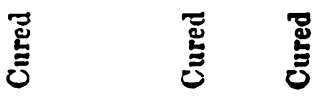

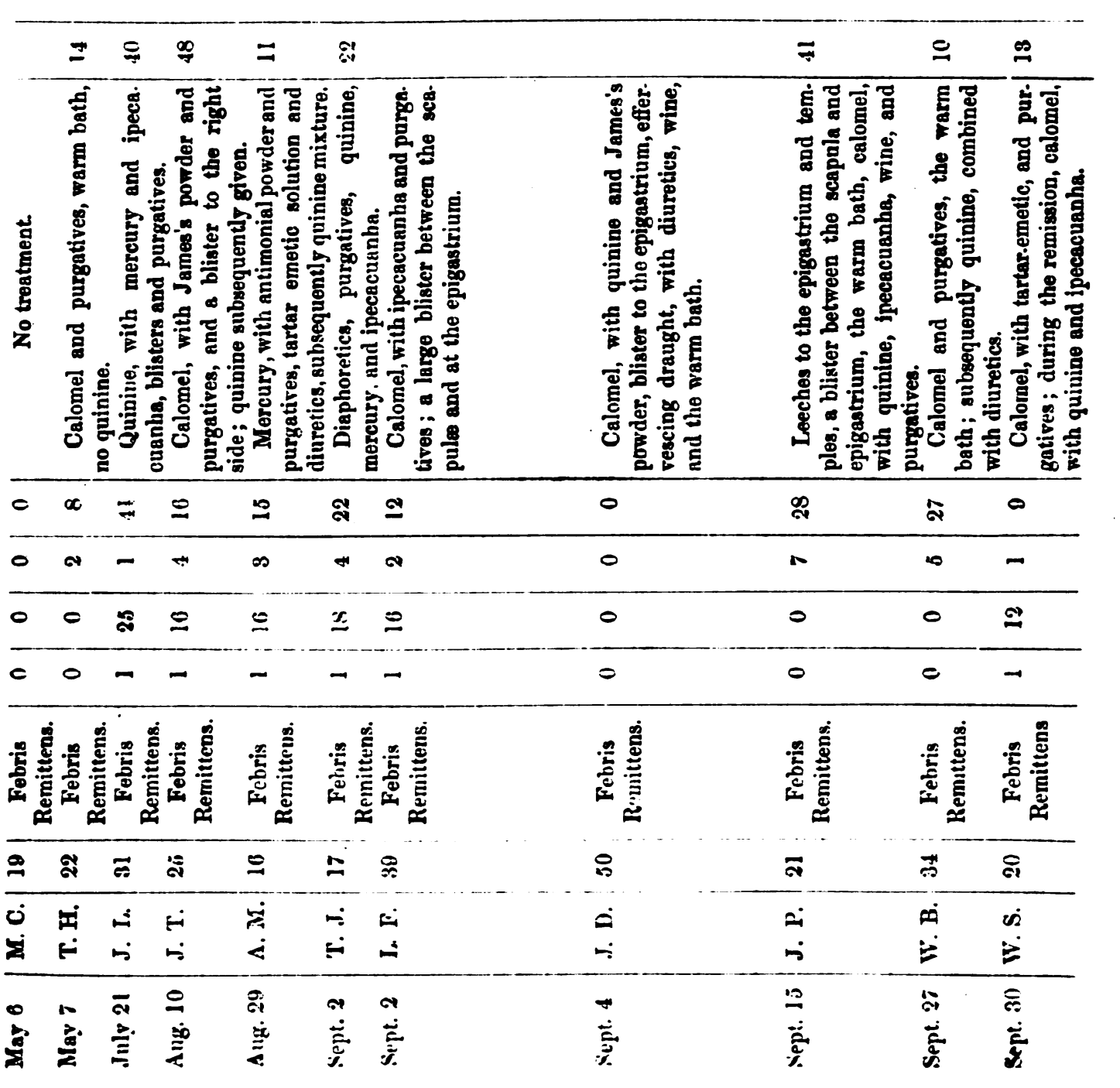




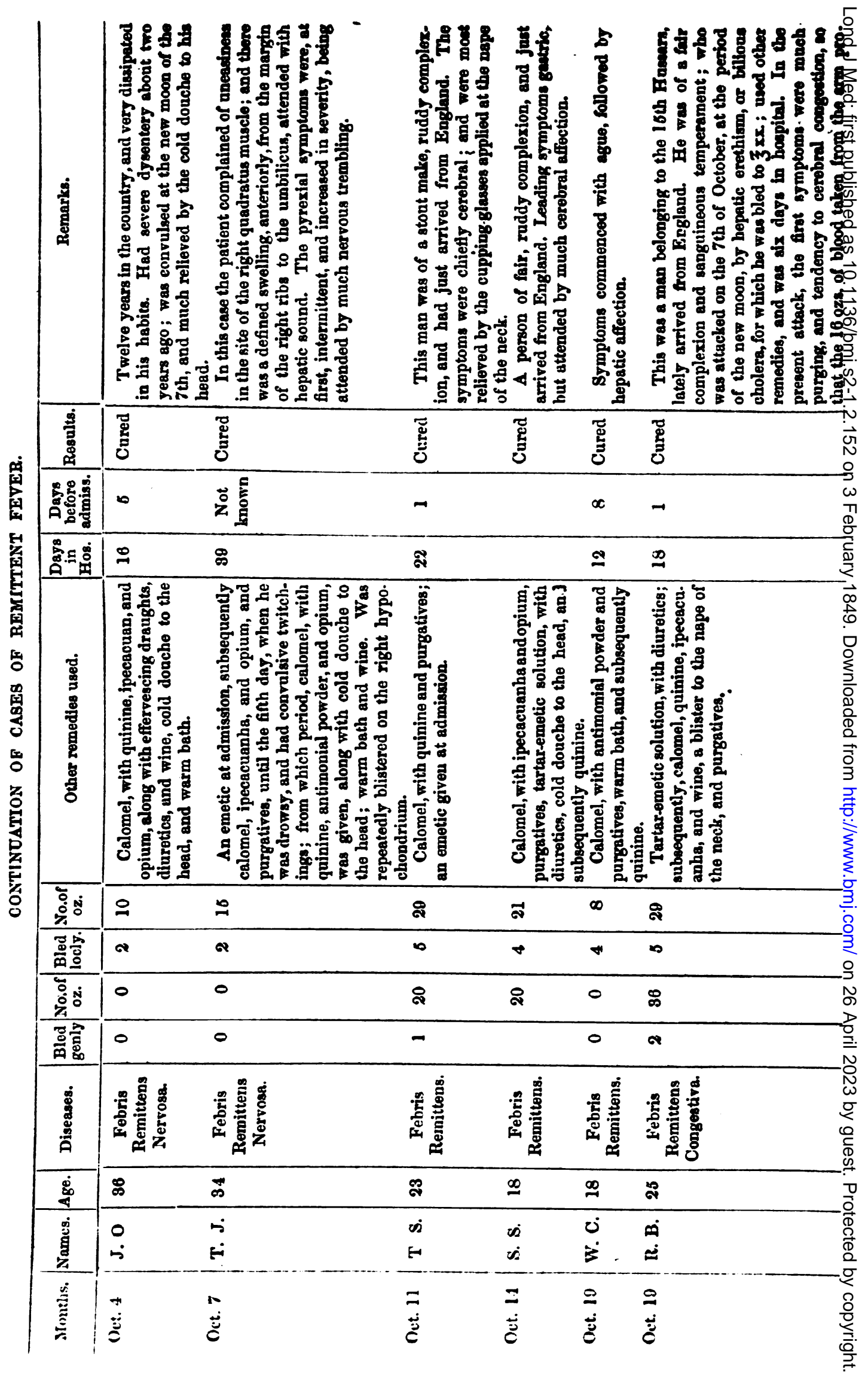




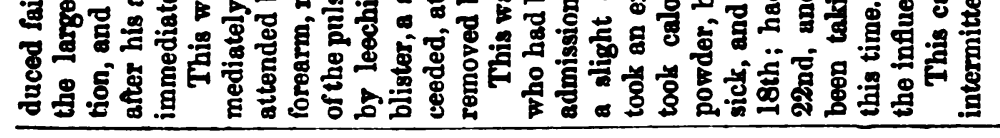

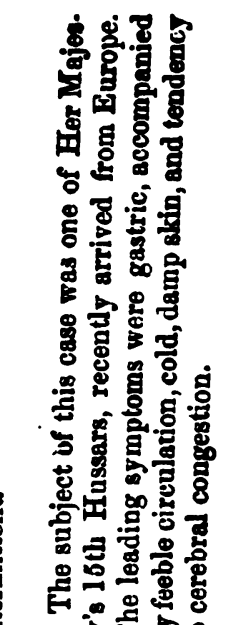

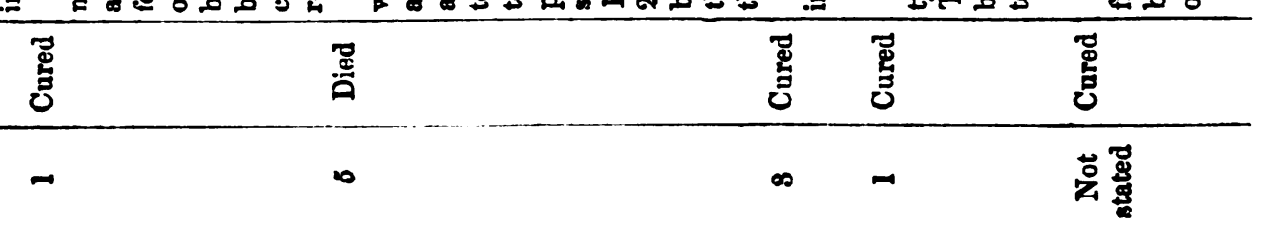






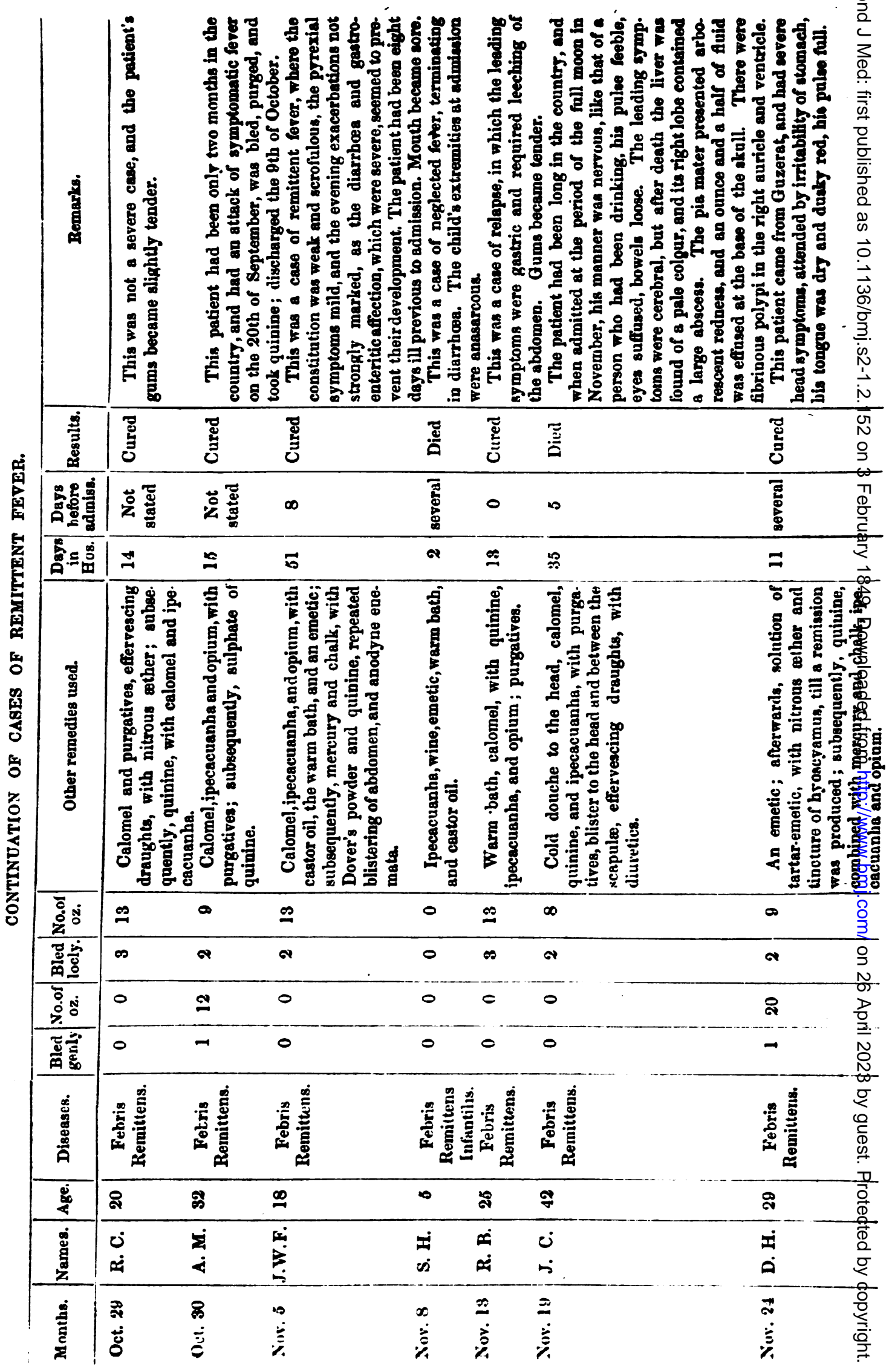


houng

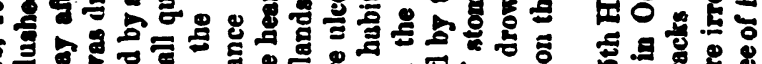

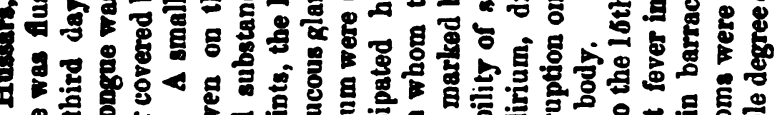

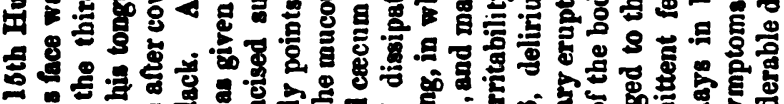

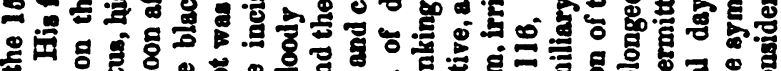
\%

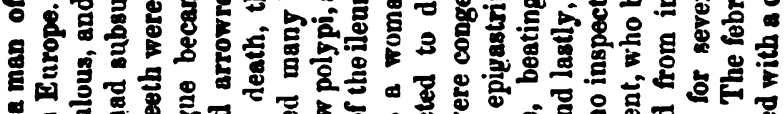

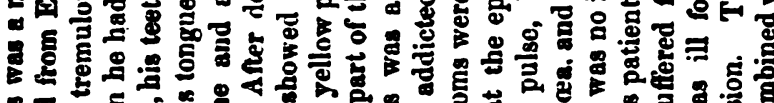

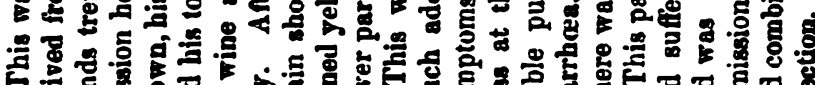

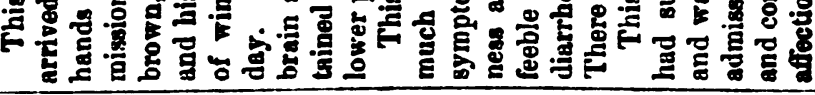

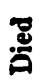

离

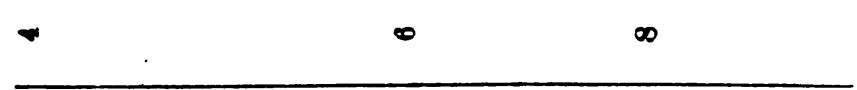

\begin{tabular}{|c|c|c|}
\hline$\infty$ & ঞ̊ & ஜூ \\
\hline 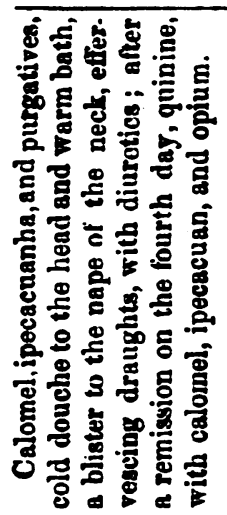 & 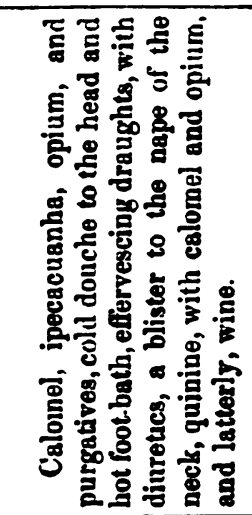 & 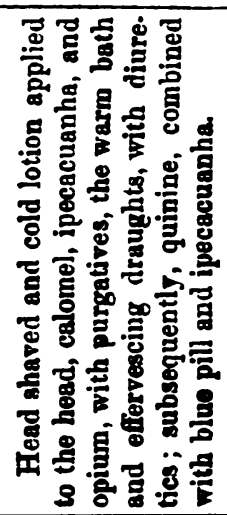 \\
\hline 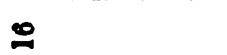 & $\infty$ & 0 \\
\hline os & $\infty$ & a \\
\hline 0 & $\begin{array}{c}\text { aAsuUY } \\
\text { 30N }\end{array}$ & 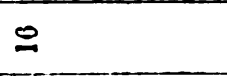 \\
\hline 0 & 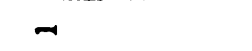 & - \\
\hline 赵 & 忢产 & 竧 \\
\hline
\end{tabular}

\begin{tabular}{|c|c|c|c|}
\hline$\vec{a}$ & & : & 1 \\
\hline$B$ & 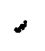 & $\ddot{x}$ & $\dot{\varphi}$ \\
\hline بـ & & $i$ & $\dot{ }$ \\
\hline $\begin{array}{l}\infty \\
\dot{\Xi} \\
\stackrel{\Xi}{\Xi}\end{array}$ & & $\begin{array}{l}\infty \\
\stackrel{0}{0}\end{array}$ & $\begin{array}{l}\ddot{\Xi} \\
\ddot{\Xi}\end{array}$ \\
\hline
\end{tabular}

00

$\infty .9$ 曽

훙형

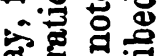

要

क

政

\&

ప.

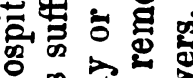

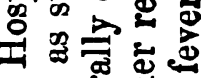

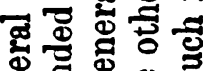

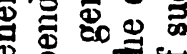

年

क्ष

$\exists$

喫

至.2

兽

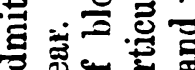

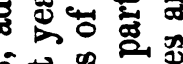

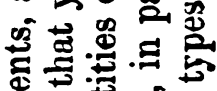

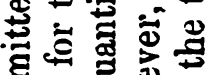

w

4

旅

莡导宗安

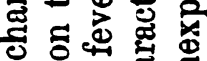

cot

范

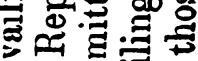

可政 $S$

的跣。

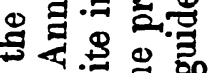

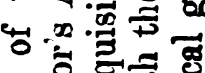

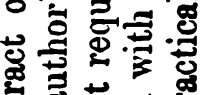

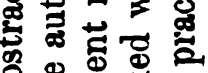

这

5 항

政

oo

要目

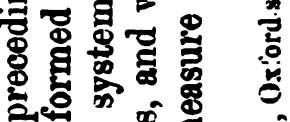

(2) 